\section{Body fat distribution and its risk for cardiovascular events in 10 years: Brazilian Longitudinal Study of Adult Health (ELSA-Brasil)}

\author{
A distribuição de gordura corporal está relacionada \\ ao risco de eventos cardiovasculares em 10 anos: \\ Estudo Longitudinal de Saúde do Adulto \\ (ELSA-Brasil)
}
La distribución de la grasa corporal está relacionada con el riesgo de eventos cardiovasculares en 10 años: Estudio Longitudinal de Salud en Adultos (ELSA-Brasil)

Bárbara Bruna Rodrigues de Oliveira 1 Carolina Gomes Coelho 2 Sandhi Maria Barreto 2 Luana Giatti 2 Larissa Fortunato Araújo 1

doi: 10.1590/0102-311X00346520

\begin{abstract}
Body fat distribution seems to have different effects in cardiovascular diseases (CVD). We aimed to estimate the associations between lower limbs and trunk fat ratio and the 10-year CVD risk, and isolated risk factors in men and women. A total of 10,917 participants from ELSA-Brasil were eligible for this cross-sectional study. Associations between lower limb/trunk fat ratio with the percentage of 10-year CVD risk - according to the Framingham Risk Score - and its risk factors (systolic blood pressure, total cholesterol and HDL-cholesterol, diabetes, and use of antihypertensive medication) were performed using generalized linear models, linear and logistic regressions. All analyses were stratified by gender and adjustments were made by age, self-reported skin color, educational attainment, alcohol consumption, leisure physical activity, hypolipidemic drug use and, for women, menopausal status. In this study, $55.91 \%$ were women, with a mean age of $52.68(S D=6.57)$ years. A higher lower limb/trunk fat ratio was related to lower 10-year CVD risk, as well as a reduction in systolic blood pressure, total cholesterol, and antihypertensive drug use, also an increasing HDL-cholesterol in both genders, but this relationship was stronger in women. Besides, a protective relationship to diabetes was observed in women. Higher fat accumulation in the lower body, when compared to the trunk, seems to have a lower risk of CVD and associated risk factors - even in the presence of fat in the abdominal region - with women presenting lower risks than men.
\end{abstract}

Body Composition; Body Fat Distribution; Cardiovascular Diseases

\author{
Correspondence \\ S. M. Barreto \\ Faculdade de Medicina, Universidade Federal de Minas Gerais. \\ Av. Alfredo Balena 110, Belo Horizonte, MG 30130-100, Brasil. \\ Sandhi.barreto@gmail.com \\ 1 Programa de Pós-graduação em Saúde Pública, Universidade \\ Federal do Ceará, Fortaleza, Brasil. \\ 2 Faculdade de Medicina, Universidade Federal de Minas \\ Gerais, Belo Horizonte, Brasil.
}




\section{Background}

Cardiovascular diseases (CVD) are the leading cause of death worldwide, corresponding to $32 \%$ (17.8 million) of deaths in 2017 1, and in all Brazilian regions 2. The body composition and body fat location are strongly related to many risk factors for CVD 3,4,5,6,7,8,9. The adipose tissue located in the abdominal area has been shown to be pathogenic and leading to metabolic disorders 10,11. Otherwise, lower body fat - including glutes, legs and hips - is considered a "metabolic sink" due to its low rate of lipolysis, fatty acid absorption, and blood flow 12 . Also, lower body fat is the most insulin sensitive adipose tissue 13 . Thus, it is inversely associated with metabolic risk factors, including hyperinsulinemia, dyslipidemia, and hypertension, as well as directly associated with the reduction in the incidence of type 2 diabetes mellitus and the occurrence of CVD 14,15.

Individual body composition is influenced by gonadal hormones 16 . Women usually accumulate fat at lower body, and men tend to accumulate it in the abdominal region. Besides, men generally have more risk factors for CVD, such as hypertension, smoking, alcohol consumption, and physical inactivity 17,18 . On the other hand, women have estrogens that protect them from CVD during childbearing age. However, these sex hormones decline after menopause 19.

Previous studies investigated the independent relationship of different body fat regions neglecting the combination among them and/or considering the presence of isolated risk factors for CVD 5,10,13,20,21,22,23,24. However, the combination of lower limbs and trunk body fat measurements seems to be more accurate to assess and to classify individuals regarding cardiovascular and metabolic risk when compared to independent measurements. Since the locations of body fat are not independent, it is possible that their effects on health are also not independent. Furthermore, those studies that evaluated fat ratio between body regions did not distinguish men and women 13,25,26, making it difficult to confirm whether there is gender effect modification. Thus, this study aims to investigate whether the higher fat ratio between lower limbs and trunk is associated with a lower risk for CVD in 10 years by the Framingham Risk Score (FRS) and its risk factors in adults and whether this relationship is stronger in women compared to men.

\section{Methods}

\section{Study type and population}

A cross-sectional study was conducted using data from the second wave of the Brazilian Longitudinal Study of Adult Health (ELSA-Brasil). ELSA-Brasil is a multicenter cohort of active and retired civil servants, aged from 35 to 74 years, from universities and research institutions located in municipalities from six Brazilian states: Belo Horizonte (Minas Gerais State), São Paulo, Rio de Janeiro, Vitória (Espírito Santo State), Salvador (Bahia State), and Porto Alegre (Rio Grande do Sul State). Its main objective is to investigate the incidence and progression of CVD and diabetes and their social, behavioral, biological, and environmental determinants. More detailed information about ELSA-Brasil can be found in previously published studies 27,28 .

Those who reported medical diagnosis for CVD $(\mathrm{n}=877)$, body mass index (BMI) below $18.5 \mathrm{~kg} / \mathrm{m}^{2}$ $(\mathrm{n}=95)$ and age equal to or above 65 years $(\mathrm{n}=2,125)$ were excluded. The exclusion of low weight individuals and older adults is due to their specific body composition, differently affecting cardiovascular risk. Furthermore, participants with missing information - due to missing answers for any question or those who did not undergone the physical measurements - were excluded in the analysis, as follows: ratio between the amounts of fat in the lower limbs and trunk $(n=692)$, self-reported skin color $(\mathrm{n}=106)$, educational attainment $(\mathrm{n}=6)$, alcohol consumption $(\mathrm{n}=11)$, physical activity $(\mathrm{n}=1)$, use of lipid-lowering medication $(\mathrm{n}=37)$, and total cholesterol $(\mathrm{n}=17)$. At the end, data from 10,047 participants were eligible for the study. 


\section{Response variable}

The response variable was the percentage of risk for CVD in 10 years, calculated using the FRS. The FRS is gender-specific and considers in its composition: age, total cholesterol, high-density level (HDL) cholesterol, systolic blood pressure, diabetes, smoking, and the use of antihypertensive drugs 28 . Variables were obtained by standardized face-to-face interviews and clinical and laboratory procedures. Participants were fasting and instructed to avoid drinking alcoholic beverages and caffeine, as well as to avoid exercising within 12 hours prior to examinations. Blood samples were collected after 10 to 14-hours fasting and stored using standardized protocol. These parameters were measured in ELSA-Brasil, as follows:

(1) Age was measured at continuous age and categorized into: $\leq 44$; 45 to $49 ; 50$ to 54 ; 55 to 59; and 60 to 64 years;

(2) Total cholesterol was analyzed by enzymatic colorimetric assay (ADVIA Chemistry; https://www. siemens-healthineers.com/br) using fasting blood samples 27 and grouped into the following ranges: < 160; 160 to $199 ; 200$ to $239 ; 240$ to 279 ; and $\geq 280 \mathrm{mg} / \mathrm{dL}$;

(3) HDL-cholesterol was analyzed by the same method as total cholesterol and grouped into the following ranges: $\geq 60 ; 50$ to $59 ; 45$ to $49 ; 35$ to 44 ; $<35 \mathrm{mg} / \mathrm{dL}$;

(4) Diabetes was defined in the same way as the FRS: use of medication to treat diabetes (insulin or hypoglycemic drugs) or fasting blood glucose $\geq 126 \mathrm{mg} / \mathrm{dL}$. Fasting blood glucose was determined by the enzymatic method (hexokinase) using the ADIVA 1200 device. The use of anti-diabetes drugs was obtained from self-report and verification of medical prescriptions and medication boxes. The drugs were classified according to Anatomical Therapeutic Chemical criteria;

(5) Blood pressure was measured with the validated Omron HEM 705CPINT oscillometric device (Omron Co.; https://www.omron.com) after a 5-minute rest in sitting position in a controlled temperature room $\left(20-24^{\circ} \mathrm{C}\right)$; the mean from the last two of the three measurements performed was used, with a one-minute interval between measurements, also obtained in the fasting period. The following cutoff points for systolic blood pressure were used: < 120; 120 to $129 ; 130$ to $139 ; 140$ to $149 ; 150$ to 159 and $\geq 160 \mathrm{mmHg}$;

(6) The information about the use of antihypertensive drugs was obtained in the same method as for anti-diabetes drugs;

(7) Participants who reported smoking at least 100-lifetime cigarettes and who reported currently smoking were categorized as "smokers". Those who reported not currently smoking were classified as non-smokers. The following questions were used to define smoker status: "Are you or have you ever been a smoker, i.e., have you smoked at least 100 cigarettes (five packs of cigarettes) in your lifetime? Do you currently smoke cigarettes?

The total point of FRS was used as continuous and categorical variables considering cutoff proposed by D'Agostino et al. 29: 0 to < 6\% (low risk), 6 to 20\% (medium risk) and > 20\% (high risk).

\section{Explanatory variable of interest}

The fat of lower body and trunk - in kilograms $(\mathrm{kg})$ - were determined by a vertical direct segmental multifrequency electrical impedance device (InBody 230; https://inbody.com/en). The equipment uses the multifrequency system (10 impedance measurements at 20 and $100 \mathrm{kHz}$ frequency) of tetrapolar electrodes with an eight-point tactile electrode. The volunteers were instructed to fast for at least 4 hours, previously empty the bladder, refrain from strenuous exercise and alcohol 24 hours prior to the test, and not use metallic fittings (e.g., watches, rings, earrings) during the test. During the evaluation, the participants remained in the study uniform to determine body weight in kilograms; and then placed their hands and feet on the instrument tactile electrodes for impedance measurement according to the manufacturer's instructions. The results of the measurement by the impedance device provided the values of percentage of fat per body compartment in kilograms. Then, the amount of fat on the trunk and lower limbs was obtained. In this analysis, exposure was investigated by lower limbs/trunk fat ratio. Lower limbs region includes glutes, hips, and legs (right and left) and trunk region includes chest, abdomen, and back (and does not include arms, neck, and head fat). 
Bioelectrical impedance analysis (BIA) measurements were performed once by trained professionals, who were certified before and throughout the study, using pre-established standard procedures, equipment, and techniques.

\section{Covariables}

The following variables related to both exposure and outcome were considered as confounders for adjustment from the most relevant similar studies that investigated this association 30,31,32,33,34,35,36, $37,38,39,40,41,42,43,44,45,46,47,48$ : age as categories in descriptive analysis $(\leq 44 ; 45$ to $49 ; 50$ to $54 ; 55$ to 59 ; and 60 to 64 years old) and as continuous in multivariate analysis - to remove residual confounding -; educational attainment [university degree or more ( $>15$ years), high school (11-14 years), complete elementary school (8-10 years) and incomplete elementary school (0-7 years)]; self-reported skin color (white, brown-skinned or pardo, black, Asian descendant and Brazilian indigenous); leisure physical activity (light, moderate, and intense) assessed by the International Physical Activity Questionnaire (IPAQ) and; regarding alcohol consumption, the participants were categorized as: drinking moderately (men, consumption < 210g of alcohol and women, consumption < 140g of alcohol per week, nonuser, and drinking excessively (men, consumption $\geq 210 \mathrm{~g}$ of alcohol and women, consumption $\geq 140 \mathrm{~g}$ of alcohol per week).

\section{Statistical analysis}

All analyses were stratified by gender. Pearson's chi-square test was performed for qualitative variables, analysis of variance (ANOVA) for quantitative variables with normal distribution, and Wilcoxon test for quantitative variables with asymmetric distribution. The mean (SD) fat amounts of lower body limbs, trunk and its ratio were compared by category of FRS using ANOVA.

Generalized linear model (GLM) with a logarithmic link and gamma distribution was used to measure the association of lower limb/trunk fat ratio with Framingham risk score for CVD. In a GLM, the exponentiation of the mean response represents the ratio of the arithmetic means (AMR) of the compared categories, which are in the same scale of the original response variable, i.e., percentage of FRS 49 .

Firstly, an unadjusted analysis of lower limb/trunk fat ratio and the FRS (Model 1) were performed. Then, sequential adjustments were made for age, self-reported skin color, educational attainment (Model 2), alcohol consumption, leisure physical activity and smoking (no/yes) for individuals FRS components models (Model 3), and finally for hypolipidemic medication use, and menopause status for women (Model 4). Subsequently, considering full adjustment, the association between lower limb/trunk fat ratio content with individual FRS components was measured using linear regression (systolic blood pressure, total cholesterol, and HDL-cholesterol) and logistic regression (diabetes and use of antihypertensive medication) according to the characteristics of each response variable. Analyses were performed using Stata 15.0 (https://www.stata.com).

\section{Ethical aspects}

The project was approved by the Brazilian National Research Ethics Committee (CONEP) in compliance with Resolution n. 196/1996 and other complementary resolutions. The research was approved by the Research Ethics Committees of the six institutions involved. All participants signed the informed consent form before conducting interviews and examinations. 


\section{Results}

Among 10,047 participants, men represented $44.09 \%$ of the total population. These men were younger, lower educated, mostly self-reported skin their color as brown-skinned or pardo; they presented excessive alcohol use, diabetes and intense leisure physical activity, higher levels of systolic blood pressure, total cholesterol, percentage of risk for CVD and lower levels of HDL-cholesterol compared to women (Table 1).

\section{Table 1}

Characteristics of the study population. Brazilian Longitudinal Study of Adult Health (ELSA-Brasil), 2012-2014.

\begin{tabular}{|c|c|c|}
\hline Characteristics & $\begin{array}{l}\text { Men } \\
\text { n (\%) }\end{array}$ & $\begin{array}{c}\text { Women } \\
\text { n (\%) }\end{array}$ \\
\hline Sex & $4,430(44.09)$ & $5,617(55.91)$ \\
\hline \multicolumn{3}{|l|}{ Age (years) * } \\
\hline$\leq 44$ & $611(13.79)$ & $691(12.30)$ \\
\hline $45-49$ & $980(22.12)$ & $1,164(20.72)$ \\
\hline $50-54$ & $1,114(25.15)$ & $1,447(25.76)$ \\
\hline $55-59$ & $965(21.78)$ & $1,277(22.73)$ \\
\hline $60-64$ & $760(17.16)$ & $1,038(18.48)$ \\
\hline \multicolumn{3}{|l|}{ Race/Skin color self-reported ** } \\
\hline White & $2,267(51.17)$ & $2,886(51.38)$ \\
\hline Brown-skinned or pardo & $1,401(31.63)$ & $1,522(27.10)$ \\
\hline Black & $630(14.22)$ & $1,004(17.87)$ \\
\hline Asian descendant & $76(1.72)$ & $161(2.87)$ \\
\hline Brazilian indigenous & $56(1.26)$ & $44(0.78)$ \\
\hline \multicolumn{3}{|l|}{ Educational attainment ** } \\
\hline University degree or more & $2,379(53.70)$ & $3,447(61.37)$ \\
\hline High school & $1,476(33.32)$ & $1,833(32.63)$ \\
\hline Complete elementary school & $306(6.91)$ & $221(3.93)$ \\
\hline Incomplete elementary school & $269(6.07)$ & $116(2.07)$ \\
\hline \multicolumn{3}{|l|}{ Alcohol consumption ** } \\
\hline Moderate & $2,643(59.66)$ & $3,172(56.47)$ \\
\hline Nonuser & $1,196(27.00)$ & $2,201(39.18)$ \\
\hline Excessive & $591(13.34)$ & $244(4.34)$ \\
\hline \multicolumn{3}{|l|}{ Physical activity ** } \\
\hline Light & $3,137(70.81)$ & 4,395 (78.24) \\
\hline Moderate & $784(17.70)$ & $876(15.60)$ \\
\hline Intense & 509 (11.49) & $346(6.16)$ \\
\hline \multicolumn{3}{|l|}{ Use of hypolipidemic } \\
\hline No & $3,693(83.36)$ & $4,650(82.78)$ \\
\hline Yes & $737(16.64)$ & $967(17.22)$ \\
\hline \multicolumn{3}{|l|}{ Menopause status } \\
\hline No & - & $1,889(34.31)$ \\
\hline Yes & - & $3,616(65.69)$ \\
\hline \multicolumn{3}{|l|}{ Smoking } \\
\hline No & $3,896(87.95)$ & 4,999 (89.00) \\
\hline Yes & $534(12.05)$ & $618(11.00)$ \\
\hline
\end{tabular}

(continues) 
Table 1 (continued)

\begin{tabular}{|c|c|c|}
\hline Characteristics & $\begin{array}{l}\text { Men } \\
\text { n (\%) }\end{array}$ & $\begin{array}{c}\text { Women } \\
\text { n (\%) }\end{array}$ \\
\hline \multicolumn{3}{|l|}{ Systolic blood pressure $(\mathrm{mg} / \mathrm{dL}) * \star$} \\
\hline$<120$ & $1,977(44.63)$ & $3,620(64.45)$ \\
\hline $120-129$ & $1,185(26.75)$ & $1,117(19.89)$ \\
\hline $130-139$ & $674(15.21)$ & $507(9.03)$ \\
\hline $140-149$ & $336(7.58)$ & $229(4.08)$ \\
\hline $150-159$ & $146(3.30)$ & $89(1.58)$ \\
\hline$\geq 160$ & $112(2.53)$ & $55(0.98)$ \\
\hline \multicolumn{3}{|l|}{ Use of antihypertensive medication } \\
\hline No & $3,053(68.92)$ & $3,867(68.84)$ \\
\hline Yes & $1,377(31.08)$ & $1,750(31.16)$ \\
\hline \multicolumn{3}{|l|}{ HDL-cholesterol (mg/dL) ** } \\
\hline$\geq 60$ & $573(12.93)$ & $2,332(41.52)$ \\
\hline $50-59$ & $1,071(24.18)$ & $1,763(31.39)$ \\
\hline $45-49$ & $848(19.14)$ & $764(13.60)$ \\
\hline $35-44$ & $1,639(37.00)$ & $685(12.20)$ \\
\hline$<35$ & $299(6.75)$ & $73(1.30)$ \\
\hline \multicolumn{3}{|l|}{ Total cholesterol (mg/dL) ** } \\
\hline$<160$ & $698(15.76)$ & $715(12.73)$ \\
\hline 160-199 & $1,825(41.20)$ & $2,236(39.81)$ \\
\hline $200-239$ & $1,408(31.78)$ & $1,910(34.00)$ \\
\hline $240-279$ & $402(9.07)$ & $615(10.95)$ \\
\hline$\geq 280$ & $97(2.19)$ & $141(2.51)$ \\
\hline \multicolumn{3}{|l|}{ Diabetes ** } \\
\hline No & $3,648(82.35)$ & $4,879(86.86)$ \\
\hline Yes & $782(17.65)$ & $738(13.14)$ \\
\hline Framingham Risk Score [median (1st-3rd quartile)] ** & $10.82(6.80-17.64)$ & $4.30(2.65-7.18)$ \\
\hline
\end{tabular}

Note: Pearson's chi-square test was performed for qualitative variables, ANOVA for quantitative variables with normal distribution, and Wilcoxon test for quantitative variables with asymmetric distribution.

* p-value $<0.05$;

$* *$-value $<0.01$.

In both genders, participants at high 10-year CVD risk had higher fat means (in kilograms) of lower body limbs and trunk compared to individuals at low and medium 10-year CVD risk (p-value $<0.01$ ). Women had higher means of fat amounts of lower body limbs and trunk in all cardiovascular risk categories when compared to men. Also, those with a low risk of CVD in 10 years showed a higher difference in means between lower limbs fat and trunk fat (p-value $<0.01$ ), and this relationship was higher in women compared to men (Table 2).

Table 3 shows the associations of lower limb/trunk fat ratio with risk for CVD. In unadjusted model (Model 1), the one-unit increase in the lower limb/trunk fat ratio reduces the risk for CVD by $38 \%$ in men (AMR: 0.62 ; 95\%CI: 0.56 ; 0.68) and $82 \%$ in women (AMR: 0.18 ; 95\%CI: $0.13 ; 0.22$ ). After completed adjustment (Model 4) we observed small changes in association magnitudes (AMR for men: 0.69 ; $95 \%$ CI: 0.64; 0.74; AMR for women: 0.23 ; 95\%CI: 0.18 ; 0.29). The associations were stronger in women compared to men.

Table 4 shows the association between the lower limb/trunk fat ratio with each individual component of FRS among men and women. The one-unit increasing in the difference between the fat locations was associated with a reduction in systolic blood pressure, total cholesterol, and antihypertensive drug use, also an increase in HDL-cholesterol in both genders, but this relationship was stronger in women. Moreover, women presented a protective relationship to diabetes. 
Table 2

Description of fat amounts of lower body limbs and trunk according to categories of risk for cardiovascular disease in 10 years. Brazilian Longitudinal Study of Adult Health (ELSA-Brasil), 2012-2014.

\begin{tabular}{lcc}
\hline FRS & $\begin{array}{c}\text { Men } \\
\text { Mean (SD) }\end{array}$ & $\begin{array}{c}\text { Women } \\
\text { Mean (SD) }\end{array}$ \\
\hline $\begin{array}{l}\text { Lower body limbs (kg) * } \\
\text { Low }\end{array}$ & \\
Medium & $5.49(1.91)$ & $7.65(2.53)$ \\
High & $6.33(2.16)$ & $8.50(2.69)$ \\
Trunk (kg) & $6.94(2.19)$ & $8.68(2.85)$ \\
Low & & \\
Medium & $10.55(4.38)$ & $13.76(4.71)$ \\
High & $12.61(4.71)$ & $15.74(4.72)$ \\
Lower limb/trunk fat ratio (kg) * & $14.17(4.64)$ & $16.29(4.98)$ \\
Low & & \\
Medium & $0.54(0.09)$ & $0.56(0.06)$ \\
High & $0.51(0.12)$ & $0.54(0.06)$ \\
& $0.49(0.07)$ & $0.53(0.07)$
\end{tabular}

FRS: Framingham Risk Score; SD: standard deviation.

Note: ANOVA test.

* All p-values were below 0.01 .

\section{Table 3}

Associations of lower limb/trunk fat ratio with risk for cardiovascular disease in 10 years. Brazilian Longitudinal Study of Adult Health (ELSA-Brasil), 2012-2014.

\begin{tabular}{lcc}
\hline Model & $\begin{array}{c}\text { Men } \\
\text { AMR }(95 \% \mathrm{Cl}) *\end{array}$ & $\begin{array}{c}\text { Women } \\
\text { AMR }(95 \% \mathrm{CI})\end{array}$ \\
\hline 1 & $0.62(0.56 ; 0.69)$ & $0.17(0.13 ; 0.22)$ \\
2 & $0.68(0.63 ; 0.73)$ & $0.22(0.17 ; 0.27)$ \\
3 & $0.69(0.64 ; 0.74)$ & $0.23(0.18 ; 0.29)$ \\
4 & $0.69(0.64 ; 0.74)$ & $0.23(0.18 ; 0.29)$ \\
\hline
\end{tabular}

95\%Cl: 95\% confidence interval; AMR: arithmetic mean ratio.

Note: performed generalized linear model with logarithmic link and gamma distribution. Model 1: unadjusted analysis; Model 2: Model $1+$ adjustment for age, self-reported skin color and educational attainment; Model 3: Model $2+$ alcohol consumption and leisure physical activity; and Model 4: Model 3 + hypolipidemic drug use and menopausal status (for women).

* All p-values were below 0.01 . 
Associations of lower limb/trunk fat ratio with cardiovascular risk factors. Brazilian Longitudinal Study of Adult Health (ELSA-Brasil), 2012-2014

\begin{tabular}{lcc}
\hline & $\begin{array}{c}\text { Men } \\
\text { Coefficient }(\mathbf{9 5 \% C l})\end{array}$ & $\begin{array}{c}\text { Women } \\
\text { Coefficient }(\mathbf{9 5 \% C l})\end{array}$ \\
\hline Total cholesterol * & $-39.83(-49.78 ;-29.88) * *$ & $-53.35(-67.12 ;-39.58) * *$ \\
HDL-cholesterol * & $18.61(15.93 ; 21.28) * *$ & $31.04(26.06 ; 36.02) * *$ \\
Systolic blood pressure * & $-12.78(-16.62 ;-8.93) * *$ & $-15.16(-20.57 ;-9.74) * *$ \\
Antihypertensive medication *** & $0.03(0.01 ; 0.12) * *$ & $0.37(0.14 ; 0.99) *$ \\
Diabetes *** & $1.03(0.37 ; 2.86)$ & $0.04(0.01 ; 0.19) * *$ \\
\hline
\end{tabular}

95\%Cl: 95\% confidence interval.

* Performed linear regression;

$* *$ p-value $<0.01$;

*** Performed logistic regression. Adjusted for age, self-reported skin color and educational attainment; alcohol consumption, smoking and leisure physical activity; hypolipidemic drug use and menopausal status (for women). \# p-value $<0.05$.

\section{Discussion}

Our study showed that the higher amount of fat in the lower limbs in relation to the trunk was associated with a lower risk of CVD in 10 years. We also observed that the highest lower limb/trunk fat ratio was associated with a reduction in systolic blood pressure, total cholesterol, and use of antihypertensive drugs, in addition to an increase in HDL-cholesterol in both genders. All associations described were stronger in women. Furthermore, women presented the highest protective relationship against diabetes.

Previous studies reinforce the evidence that higher fat in the lower body limbs has a protective relationship for CVD 21,26,50,51, while an elevated fat percentage located in the trunk increases its occurrence 11,23,30,52,53. For example, in a longitudinal study using data from 15,686 individuals of National Health and Nutrition Examination Survey (NHANES) without history of CVD, the highest lower limb/trunk fat ratio was related to lower waist circumference, blood pressure, glucose levels, insulin resistance, LDL cholesterol and triglycerides, higher HDL-cholesterol levels and better glomerular filtration rate 21 .

In our study - although considering all 10-year cardiovascular risk categories - women presented a higher amount of fat in the lower limbs and trunk, also presenting a higher difference compared to men. In addition, after adjusting for all covariables, the protective relationship of lower limb fat remained statistically significant in both genders, with a stronger relationship for women. Similar results were also found in the Characteristics and Course of Heart Failure Stages A-B and Determinants of Progression (STAAB) Cohort Study conducted with 980 participants (aged 30-79 years), which used the SCORE algorithm to estimate cardiovascular risk at 10 years. Women had a higher prevalence of general obesity, but a lower risk of CVD in 10 years 31 . A higher magnitude of association was also found among women compared to men in a cross-sectional study of 4,256 Japanese (aged 20-79 years), in which the higher amount of fat in the lower limbs was associated with a lower risk of developing cardiovascular events 32 .

The same was observed in 4,950 participants (2,119 men and 2,831 women) aged 29 to 55 years at the Oxford Biobank, in which women presented higher amounts of fat in the lower limbs, while men in the trunk. An increase in lower limbs mass at any trunk fat level was generally associated with lower fasting glucose, triglycerides, HOMA-IR, and mean blood pressure, which had a protective relationship on cardiovascular risk and this relationship was somewhat stronger in women ${ }^{30}$. However, other studies have found significant associations only among men $33,34,35$. Such studies included adults and older people and the absence of statistical significance in women may be due to a large number of older women and/or a lack of adjustment for potential confounding variables. 
Our results were not affected by these factors, since the analyses were adjusted for the presence of menopause, and people aged over 64 were excluded from our study, removing the possibility of confounding or effect modification by advanced ages. Even if women have some protection from CVD due to increased fat accumulation in the lower limbs, menopause leads to a decline in sex hormones (estrogen and progesterone), increasing fat in the trunk region and consequently increasing the CVD risk 36,37. However, a favorable and low-risk profile on CVD in postmenopausal women using hormone replacement therapy was observed in previous studies 38,39,40,41,42,43,44,45,46.

Nevertheless, in the Women's Health Initiative (WHI) cohort study of 2,683 postmenopausal U.S. women (aged 50-79 years), without CVD at baseline, with normal weight (BMI: 18.5 to $24.9 \mathrm{~kg} / \mathrm{m}^{2}$ ) and using hormone replacement therapy, the higher amount of trunk fat mass compared to lower body limbs was associated higher blood pressure, insulin resistance, HOMA-IR, adipokines (leptin and adiponectin), inflammatory markers [leukocyte count, high sensitivity C-reactive protein (CRP) and interleukin-6], lipids (triglycerides and LDL cholesterol). Thus, postmenopausal women with a higher trunk fat and lower limbs fat had a three times higher risk of CVD compared to those with opposite values of higher fat amount on lower body limbs and lower trunk fat, even when considering adjustment for hormone replacement therapy 47.

A systematic review study concluded that the sex chromosome might influence factors underlying metabolic disorders such as obesity, dyslipidemia, and inflammation. It is well known that gonadal hormones have substantial effects on fat storage and susceptibility to CVD and type 2 diabetes among men and women. Thus, essential differences between genders can be found regarding the distribution of adipose tissue in the body, with men accumulating higher amounts of visceral adipose tissue and women with higher fat accumulation in the subcutaneous (lower body limbs) deposits 48 .

Specific associations between body fat regions and risk factors for CVD are plausible, as the upper and lower body contains divergent fat deposits with profoundly distinct biological functions 14,47. Several mechanisms potentially responsible for these adipose deposition-dependent associations have been proposed, including regional differences in the severity of adipose inflammation, lipid storage and renewal, adipokine release, and endocrine effects 13,14,54. Even for similar types of fat, leg adipose tissue was less susceptible to the unregulated release of free fatty acids, resulting in lipotoxicity than abdominal subcutaneous adipose tissue, reinforcing the hypothesis that lower body deposits are the ideal site for fat storage $35,47,55$.

Some limitations need to be considered when interpreting our results. Firstly, since we performed a cross-sectional analysis, we have no temporality between body composition and FRS components and cannot claim causality. We did not evaluate the body composition through the dual-energy X-ray absorptiometry (DXA) method, which is the gold standard for this measurement - although it is not the most adequate method for large population epidemiological studies - in the use of practical clinical evaluations.

Moreover, we used bioelectrical impedance, a cheaper and less invasive method compared to DXA, because numerous studies have investigated the validity of BIA for measuring body composition, comparing its results with DXA, and these studies reported that BIA showed good overall agreement with DXA in healthy adults. All comparisons between measurements provided by BIA and DXA showed strong significant correlations between both methods, acceptable limits of agreement for body fat percentage and absence of significant biases between BIA and DXA 56,57,58,59,60,61. Our study was conducted in a multicenter study population with a large sample size and geographical diversity, allowing us to include subjects with different cultural and racial characteristics. Furthermore, it was developed in a low- and middle-income country with a high and growing prevalence of overweight and obese people, which is a current public health problem - reinforcing the relevance of understanding the role of fat localization in the risk of CVD. We stratified the analysis by gender, allowing us to verify the differences between men and women in the pattern of fat accumulation that led to higher or lower risk for developing CVD. Furthermore, we removed effects from potential confounders of this relationship such as sociodemographic characteristics, health behaviors and conditions. 


\section{Conclusion}

Our results suggest that higher fat amount in the lower limbs in relation to the trunk exerts a lower risk of CVD in 10 years and this relationship is stronger in women compared to men. When a population is dealing with an epidemic of overweight and obesity it is essential to understand the patterns of body fat accumulation and the different ways it affects the development of CVD. This knowledge also supports the optimization of health spending, since it targets specific actions for at-risk populations and reduce morbidity and mortality.

\section{Contributors}

B. B. R. Oliveira, L. F. Araújo, and C. G. Coelho contributed to the study conceptualization, methodology, data analysis, writing, and review. S. M. Barreto and L. Giatti contributed to the data analysis and review. All authors approved the final version of the manuscript.

\section{Additional informations}

ORCID: Bárbara Bruna Rodrigues de Oliveira (0000-0001-6726-9176); Carolina Gomes Coelho (0000-0002-7294-3724); Sandhi Maria Barreto (0000-0001-7383-7811); Luana Giatti (0000-00015454-2460); Larissa Fortunato Araújo (0000-00016695-0365).

\section{Acknowledgments}

The authors thank the staff and participants of the ELSA-Brasil for their important contributions. To the Brazilian National Research Council (CNPq), Brazilian Graduate Studies Coordinating Board (CAPES), and the Brazilian Funding Authority for Studies and Projects (FINEP).

\section{References}

1. GBD 2017 Causes of Death Collaborators. Global, regional, and national age-sex-specific mortality for 282 causes of death in 195 countries and territories, 1980-2017: a systematic analysis for the Global Burden of Disease Study 2017. Lancet 2018; 392:1736-88.

2. Freitas RS, Fonseca MJM, Schmidt MI, Molina MCB, Almeida MCC. Fenótipo cintura hipertrigliceridêmica: fatores associados e comparação com outros indicadores de risco cardiovascular e metabólico no ELSA-Brasil. Cad Saúde Pública 2018; 34:e00067617.

3. Bahia L, Araújo DV. Impacto econômico da obesidade no Brasil. Revista HUPE 2014; 13:13-7.

4. Bastien M, Poirier P, Lemieux I, Després JP. Overview of epidemiology and contribution of obesity to cardiovascular disease. Prog Cardiovasc Dis 2014; 56:369-81.

5. Santi Cano MJ. Obesity and cardiovascular risk factors. Obes Control Ther 2013; 1:1-9.

6. Cercato C, Fonseca FA. Cardiovascular risk and obesity. Diabetol Metab Syndr 2019; 11:74.

7. Chandra A, Neeland IJ, Berry JD, Ayers CR, Rohatgi A, Das SR, et al. The relationship of body mass and fat distribution with incident hypertension: observations from the dallas heart study. J Am Coll Cardiol 2014; 64:9971002.

8. Sato F, Maeda N, Yamada T, Namazui H, Fukuda S, Natsukawa T, et al. Association of epicardial, visceral, and subcutaneous fat with cardiometabolic diseases. Circ J 2018; 82:502-8.

9. Gruzdeva O, Borodkina D, Uchasova E, Dyleva Y, Barbarash O. Localization of fat depots and cardiovascular risk. Lipids Health Dis 2018; 17:218. 
10. Neeland IJ, Turer AT, Ayers CR, Berry JD, Rohatgi A, Das SR, et al. Body fat distribution and incident cardiovascular disease in obese adults. J Am Coll Cardiol 2015; 65:2150-1.

11. Manolopoulos KN, Karpe F, Frayn KN. Gluteofemoral body fat as a determinant of metabolic health. Int J Obes 2010; 34:949-59.

12. Hornby C, Botfield H, O'Reilly MW, Westgate C, Mitchell J, Mollan SP, et al. Evaluating the fat distribution in idiopathic intracranial hypertension using dual-energy $\mathrm{X}$-ray absorptiometry scanning. Neuroophthalmology 2018; 42:99-104.

13. Karpe F, Pinnick KE. Biology of upper-body and lower-body adipose tissue: link to wholebody phenotypes. Nat Rev Endocrinol 2015; 11:90-100.

14. Tchkonia T, Thomou T, Zhu Y, Karagiannides I, Pothoulakis C, Jensen MD, et al. Mechanisms and metabolic implications of regional differences among fat depots. Cell Metab 2013; 17:644-56.

15. Peters SAE, Huxley RR, Sattar N, Woodward $M$. Sex differences in the excess risk of cardiovascular diseases associated with type 2 diabetes: potential explanations and clinical implications. Curr Cardiovasc Risk Rep 2015; 9:36.

16. Wagner KJP, Bastos JLD, Navarro A, Gonzalez-Chica DA, Boing AF. Posição socioeconômica na infância e obesidade em adultos: estudo de base populacional. Rev Saúde Pública 2018; 52:15.

17. Medeiros Filho RDA, Maciel APF, Pimenta HB, Caldeira AP. Prevalence of behaviors and risk factors for cardiovascular diseases in hypertensive population in the north of Minas Gerais, Brazil. Rev Pesqui (Univ. Fed. Estado Rio J.) 2018; 10:90.

18. Jousilahti P, Laatikainen T, Peltonen M, Borodulin K, Männistö S, Jula A, et al. Primary prevention and risk factor reduction in coronary heart disease mortality among working aged men and women in eastern Finland over 40 years: population based observational study. BMJ 2016; 352:i721.

19. Manson JE, Bassuk SS. Biomarkers of cardiovascular disease risk in women. Metabolism 2015; 64(3 Suppl 1):S33-9.

20. Wu H, Qi Q, Yu Z, Sun Q, Wang J, Franco OH, et al. Independent and opposite associations of trunk and leg fat depots with adipokines, inflammatory markers, and metabolic syndrome in middle-aged and older Chinese men and women. J Clin Endocrinol Metab 2010; 95:4389-98.

21. Han E, Lee YH, Lee BW, Kang ES, Lee IK, Cha BS. Anatomic fat depots and cardiovascular risk: a focus on the leg fat using nationwide surveys (KNHANES 2008-2011). Cardiovasc Diabetol 2017; 16:54.

22. Britton KA, Massaro JM, Murabito JM, Kreger BE, Hoffmann U, Fox CS. Body fat distribution, incident cardiovascular disease, cancer, and all-cause mortality. J Am Coll Cardiol 2013; 62:921-5.
23. Lee JJ, Pedley A, Therkelsen KE, Hoffmann U, Massaro JM, Levy D, et al. Upper body subcutaneous fat is associated with cardiometabolic risk factors. Am J Med 2017; 130:958-966.e1.

24. Goodpaster BH, Krishnaswami S, Harris TB, Katsiaras A, Kritchevsky SB, Simonsick EM, et al. Obesity, regional body fat distribution, and the metabolic syndrome in older men and women. Arch Intern Med 2005; 165:777-83.

25. Yim JE, Heshka S, Albu JB, Heymsfield S, Gallagher D. Femoral-gluteal subcutaneous and intermuscular adipose tissues have independent and opposing relationships with CVD risk. J Appl Physiol 2008; 104:700-7.

26. Mališová L, Rossmeislová L, Kováčová Z, Kračmerová J, Tencerová M, Langin D, et al. Expression of inflammation-related genes in gluteal and abdominal subcutaneous adipose tissue during weight-reducing dietary intervention in obese women. Physiol Res 2014; 63:73-82.

27. Aquino EML, Barreto SM, Bensenor IM, Carvalho MS, Chor D, Duncan BB, et al. Brazilian Longitudinal Study of Adult health (ELSABrasil): objectives and design. Am J Epidemiol 2012; 175:315-24.

28. Aquino EML, Araujo MJ, Almeida MCC, Conceição P, Andrade CR, Cade NV, et al. Participants recruitment in ELSA Brasil (Brazilian Longitudinal Study for Adult Health). Rev Saúde Pública 2013; 47:10-8.

29. D'Agostino RB, Vasan RS, Pencina MJ, Wolf PA, Cobain M, Massaro JM, et al. General cardiovascular risk profile for use in primary care: the Framingham Heart Study. Circulation 2008; 117:743-53.

30. Vasan SK, Osmond C, Canoy D, Christodoulides C, Neville MJ, Di Gravio C, et al. Comparison of regional fat measurements by dualenergy X-ray absorptiometry and conventional anthropometry and their association with markers of diabetes and cardiovascular disease risk. Int J Obes 2018; 42:850-7.

31. Tiffe T, Wagner M, Rücker V, Morbach C, Gelbrich G, Störk S, et al. Control of cardiovascular risk factors and its determinants in the general population - findings from the STAAB cohort study. BMC Cardiovasc Disord 2017; $17: 276$.

32. Sakai Y, Ito H, Egami Y, Ohoto N, Hijii C, Yanagawa M, et al. Favourable association of leg fat with cardiovascular risk factors. J Intern Med 2005; 257:194-200.

33. Wiklund P, Toss F, Jansson JH, Eliasson M, Hallmans G, Nordström A, et al. Abdominal and gynoid adipose distribution and incident myocardial infarction in women and men. Int $\mathrm{J}$ Obes 2010; 34:1752-8.

34. Mohebi R, Bozorgmanesh M, Azizi F, Hadaegh F. Effects of obesity on the impact of shortterm changes in anthropometric measurements on coronary heart disease in women. Mayo Clin Proc 2013; 88:487-94. 
35. Lotta LA, Wittemans LBL, Zuber V, Stewart ID, Sharp SJ, Luan J, et al. Association of genetic variants related to gluteofemoral vs abdominal fat distribution with type 2 diabetes, coronary disease, and cardiovascular risk factors. JAMA 2018; 320:2553-63.

36. Appelman Y, van Rijn BB, ten Haaf ME, Boersma E, Peters SAE. Sex differences in cardiovascular risk factors and disease prevention. Atherosclerosis 2014; 241:211-8.

37. Van Pelt RE, Evans EM, Schechtman KB, Ehsani AA, Kohrt WM. Contributions of total and regional fat mass to risk for cardiovascular disease in older women. Am J Physiol Endocrinol Metab 2002; 282:E1023-8.

38. Villa P, Amar ID, Shachor M, Cipolla C, Ingravalle F, Scambia G. Cardiovascular risk/benefit profile of MHT. Medicina (Kaunas) 2019; 55:571.

39. Chester RC, Kling JM, Manson JAE. What the Women's Health Initiative has taught us about menopausal hormone therapy. Clin Cardiol 2018; 41:247-52.

40. Langer RD. The evidence base for HRT: what can we believe? Climacteric 2017; 20:91-6.

41. Mikkola TS, Tuomikoski P, Lyytinen H, Korhonen P, Hoti F, Vattulainen P, et al. Estradiol-based postmenopausal hormone therapy and risk of cardiovascular and all-cause mortality. Menopause 2015; 22:976-83.

42. Schierbeck LL, Rejnmark L, Tofteng CL, Stilgren L, Eiken P, Mosekilde L, et al. Effect of hormone replacement therapy on cardiovascular events in recently postmenopausal women: randomised trial. BMJ 2012; 345:e6409.

43. Stuenkel CA, Davis SR, Gompel A, Lumsden MA, Murad MH, Pinkerton JV, et al. Treatment of symptoms of the menopause: an endocrine society clinical practice guideline. J Clin Endocrinol Metab 2015; 100:3975-4011.

44. Harman SM, Black DM, Naftolin F, Brinton EA, Budoff MJ, Cedars MI, et al. Arterial imaging outcomes and cardiovascular risk factors in recently menopausal women: a randomized trial. Ann Intern Med 2014; 161:249-60.

45. Grossman DC, Curry SJ, Owens DK, Barry MJ, Davidson KW, Doubeni CA, et al. Hormone therapy for the primary prevention of chronic conditions in postmenopausal women US Preventive Services Task Force recommendation statement. JAMA 2017; 318:2224-33.

46. Committee Opinion No. 603: evaluation of uncomplicated stress urinary incontinence in women before surgical treatment. Obs Gynecol 2014; 123:1403-7.

47. Chen G-C, Arthur R, Iyengar NM, Kamensky V, Xue X, Wassertheil-Smoller S, et al. Association between regional body fat and cardiovascular disease risk among postmenopausal women with normal body mass index. Eur Heart J 2019; 40:2849-55.

48. Zore T, Palafox M, Reue K. Sex differences in obesity, lipid metabolism, and inflammation a role for the sex chromosomes? Mol Metab 2018; 15:35-44.
49. Lindsey JK, Jones B. Choosing among generalized linear models applied to medical data. Stat Med 1998; 17:59-68

50. Ofori EK, Intiful FD, Asante M, Asare GA, Adjei PK, Steele-Dadzie RK, et al. Prevalence of cardiovascular disease risk factors among students of a tertiary institution in Ghana. Food Sci Nutr 2018; 6:381-7.

51. Després JP. Body fat distribution and risk of cardiovascular disease: an update. Circulation 2012; 126:1301-13.

52. Fox CS, Massaro JM, Hoffmann U, Pou KM, Maurovich-Horvat P, Liu CY, et al. Abdominal visceral and subcutaneous adipose tissue compartments: association with metabolic risk factors in the Framingham Heart Study. Circulation 2007; 116:39-48.

53. Pou KM, Massaro JM, Hoffmann U, Vasan RS, Maurovich-Horvat P, Larson MG, et al. Visceral and subcutaneous adipose tissue volumes are cross-sectionally related to markers of inflammation and oxidative stress: the Framingham Heart Study. Circulation 2007; 116:1234-41.

54. Stefan N, Schick F, Häring HU. Causes, characteristics, and consequences of metabolically unhealthy normal weight in humans. Cell Metab 2017; 26:292-300.

55. Lüscher TF. Novel insights into body fat distribution and cardiometabolic risk. Eur Heart J 2019; 40:2833-6.

56. Gibson AL, Holmes JC, Desautels RL, Edmonds LB, Nuudi L. Ability of new octapolar bioimpedance spectroscopy analyzers to predict 4-component-model percentage body fat in Hispanic, black, and white adults. Am J Clin Nutr 2008; 87:332-8.

57. Jaffrin MY. Body composition determination by bioimpedance: an update. Curr Opin Clin Nutr Metab Care 2009; 12:482-6.

58. Lim JS, Hwang JS, Lee JA, Kim DH, Park KD, Jeong JS, et al. Cross-calibration of multi-frequency bioelectrical impedance analysis with eight-point tactile electrodes and dual-energy X-ray absorptiometry for assessment of body composition in healthy children aged 6-18 years. Pediatr Int 2009; 51:263-8.

59. Ling CH, de Craen AJ, Slagboom PE, Gunn DA, Stokkel MP, Westendorp RG, et al. Accuracy of direct segmental multi-frequency bioimpedance analysis in the assessment of total body and segmental body composition in middle-aged adult population. Clin Nutr 2011; 30:610-5.

60. Pietrobelli A, Rubiano F, St-Onge MP, Heymsfield SB. New bioimpedance analysis system: improved phenotyping with whole-body analysis. Eur J Clin Nutr 2004; 58:1479-84.

61. Karelys AD, Chamberland G, Aubertin-Leheudre M, Duval C; Ecological Mobility in Aging and Parkinson (EMAP) Group. Validation of a portable bioelectrical impedance analyzer for the assessment of body composition. Appl Physiol Nutr Metab 2013; 38:27-32. 


\section{Resumo}

A distribuição de gordura no corpo parece ter efeitos diferentes nas doenças cardiovasculares (DCV). Objetivou-se estimar as associações da razão de gordura entre membros inferiores e tronco com o risco de DCV em 10 anos e os fatores de risco independentes em homens e mulheres. Um total de 10.917 participantes do ELSA-Brasil eram elegiveis para este estudo transversal. As associações da razão de gordura entre os membros inferiores e tronco com o percentual de risco de $D C V$ em 10 anos, de acordo com a Escala de Risco de Framingham, e os respectivos fatores de risco (pressão arterial sistólica, colesterol total e HDL colesterol, diabetes e uso de medicação anti-hipertensiva), foram avaliados com modelos lineares generalizados, lineares e de regressão logística. Todas as análises foram estratificadas por sexo, e os ajustes foram feitos por idade, raça/cor, escolaridade, consumo de álcool, atividade física, uso de medicação hipolipemiante e, para as mulheres, estado de menopausa. Na amostra do estudo atual, 55,91\% eram mulheres, com média de idade de 52,68 anos $(D P=6,57)$. A maior diferença entre a gordura dos membros inferiores e tronco foi associada com menor risco de DCV em 10 anos e com redução na pressão arterial sistólica, colesterol total e uso de medicação anti-hipertensiva, assim como um aumento no HDL colesterol em ambos os sexos (mas essa correlação foi mais forte em mulheres). Além disso, foi observada uma relação protetora contra diabetes, apenas em mulheres. O acúmulo maior de gordura nos membros inferiores, comparado com o tronco, parece estar associado a um risco menor de DCV e aos fatores de risco, mesmo na presença de gordura na região abdominal, e esse efeito é mais forte nas mulheres que nos homens.

Composição Corporal; Distribuição da Gordura Corporal; Doenças Cardiovasculares

\section{Resumen}

Las distribuciones de grasa corporal parecen tener diferentes efectos en las enfermedades cardiovasculares (ECV). Nuestro objetivo fue estimar las asociaciones entre extremidades inferiores/ratio de grasa troncal y el riesgo de ECV a los 10 años, $y$ sus factores de riesgo aislados, en hombres y mujeres. Un total de 10.917 participantes de ELSABrasil fueron elegibles para este estudio transversal. Las asociaciones de la ratio de grasa entre la parte inferior del cuerpo y el tronco, con el porcentaje de riesgo de ECV a los 10 años, según la Escala de Riesgo de Framingham, y sus factores de riesgo (presión sanguínea sistólica, colesterol total y colesterol HDL, diabetes, y uso de medicación antihipertensiva), se realizaron usando modelos lineales generalizados, regresiones lineales y logísticas. Todos los análisis fueron estratificados por sexo y los ajustes se hicieron por edad, razal color de piel autoinformado, nivel educativo, consumo de alcohol, actividad física durante el ocio, uso de medicamentos hipolipemiantes $y$, para mujeres, estatus menopáusico. En este estudio, un $55,91 \%$ fueron mujeres, con una media de edad de $52,68(S D=6,57)$ años. Una ratio de masa adiposa más alta entre las extremidades inferiores/ tronco estuvo asociada a un riesgo menor de ECV en 10 años, también una reducción en la presión sistólica sanguínea, colesterol total, y el consumo de medicamentos antihipertensivos, también en un incremento del colesterol HDL en ambos sexos, pero esta relación fue más fuerte en mujeres. Asimismo, una relación protectora frente a la diabetes se observó solo en mujeres. Una acumulación más alta de grasa en las extremidades inferiores, comparada con la del tronco, parece tener un riego más bajo de ECV y sus factores de riesgo, incluso con la presencia de grasa en la región abdominal, además este efecto es más fuerte en mujeres comparadas con los hombres.

Composición Corporal; Distribución de la Grasa Corporal; Enfermedades Cardiovasculares

Submitted on 14/Dec/2020

Final version resubmitted on 10/Apr/2021

Approved on 26/Apr/2021 